\title{
Neutrophils to Lymphocytes Ratio (NLR) Variation in Relationship with Childhood Maltreatment in Patients with Anorexia Nervosa: A Retrospective Cohort Study
}

Rami Bou khalil ( $\nabla$ ramiboukhalil@hotmail.com )

Saint Jospeh University https://orcid.org/0000-0003-1725-4755

\section{Nathan Risch}

University of Montpellier

\section{Ghassan Sleilaty}

Saint Joseph University

Sami Richa

Saint Joseph University

Maude Seneque

University of Montpellier

\section{Patrick Lefebvre}

University of Montpellier

\section{Ariane Sultan}

University of Montpellier

\section{Antoine Avignon}

Saint Joseph University

\section{Laurent Maimoun}

University of Montpellier

\section{Eric Renard}

University of Montpellier

Philippe Courtet

University of Montpellier

\section{Sebastien Guillaume}

University of Montpellier

\section{Research Article}

Keywords: Anorexia Nervosa, Childhood Trauma, Inflammation, NLR, Emotional Abuse

Posted Date: October 20th, 2021

DOl: https://doi.org/10.21203/rs.3.rs-919724/v1

License: (c) (i) This work is licensed under a Creative Commons Attribution 4.0 International License. Read Full License

Version of Record: A version of this preprint was published at Eating and Weight Disorders - Studies on Anorexia, Bulimia and Obesity on February 7th, 2022. See the published version at https://doi.org/10.1007/s40519-022-01372-z. 


\section{Abstract}

Purpose: Anorexia nervosa (AN) is a serious mental illness that is frequently accompanied with a history of childhood maltreatment (CM) which may constitute a specific ecophenotype of the eating disorder necessitating special assessment and management. Chronic stress inflicted by $\mathrm{CM}$ in patients with AN may manifest through increased low grade inflammation reflected by an increase in ratios from white blood cells count such as neutrophils to lymphocytes ratio (NLR) platelets to lymphocytes ratio (PLR) and monocytes to lymphocytes ratio (MLR).

Methods: $\mathrm{N}=206$ participants were evaluated in an eating disorders daycare unit in Montpellier, France between March 2013 and January 2020. CM was assessed using childhood trauma questionnaire (CTQ). AN clinical severity was assessed using eating disorder examination (EDE-Q). The MINI was used to assess other clinical characteristics.

Results: NLR has been found to be higher in patients with AN and a history of CM $(p=0.029)$ as well as in patients with AN and a history of emotional abuse $(p=0.021)$ when compared to patients with AN and without a history of $\mathrm{CM}$. In the multivariate analysis, emotional abuse $(\beta=0.17 ; p=0.027)$ contributed significantly to NLR's variability.

Conclusion: NLR is a low grade inflammation marker that is influenced by multiple sociodemographic, clinical and biological factors in patients with AN. It is more directly affected by certain subtypes of CM, especially emotional abuse than by the presence or absence of a history of CM. Future studies may focus on mediators between CM and increased inflammation such as interoceptive awareness, emotional dysregulation, food addiction and stress-sensitization.

Level of evidence: Level III: Evidence obtained from well-designed cohort or case-control analytic studies

\section{What Is Already Known On This Subject?}

It is already known that NLR, as a low grade inflammation marker, is increased in some mental disorders. It is also known that psychological stress as well as AN are accompanied with an inflammatory state.

What this study adds? This study demonstrates that patients with AN and CM have higher NLR. In addition, when controlling for possible confounding factors, patients with emotional abuse still manifest a higher inflammatory state as reflected by a higher NLR. This might be an association that contributes to the psychopathogenesis of AN in this population subgroup.

\section{Introduction}

Anorexia nervosa (AN) is a serious mental illness estimated to affect $0.5 \%-1 \%$ of women during their lifetime and approximately one tenth as many men with a crude mortality rate of approximately $5.6 \%$ per decade of illness [1]. It is characterized by a restriction in energy intake, body-image disturbance, undue influence of body image on self-evaluation, and an intense fear of weight gain [2]. Childhood maltreatment (CM) is the abuse (emotional, sexual or physical) and neglect (emotional and physical) that occurs to children under 18 years of age which results in actual or potential harm to the child's health, survival, development, or dignity [3]. CM is known to be a non-specific risk factor for eating disorders in general and AN in particular [4, 5]. Emotional dysregulation, post-traumatic stress disorder, depression and food addiction have been considered as potential mediators between $\mathrm{CM}$ and all subtypes of eating disorders including AN [6-10].

Patients with AN and a history of CM might constitute a different ecophenotype than patients with AN without CM, possibly due to chronic activation of the hypothalamo-pituitary adrenal (HPA) axis [11,12]. As a matter of fact, emerging evidence has demonstrated that childhood trauma exposure has persistent detrimental effects on the HPA axis reactivity to a psychosocial stressor in adults with AN [11]. Moreover, it seems that the ecophenotype of patients with AN and a history of CM has been more exposed to a specific type of CM such as emotional abuse [11, 12]. From another perspective, it is becoming more accepted that stress influences the HPA axis and autonomous nervous system and, ultimately, the immune system which may increase proinflammatory cytokine levels and lymphocytes activation mainly through norepinephrine secretion, oxidative stress and sleep disturbance [13-15]. During the last decade, preclinical and clinical studies have started to emerge in which, aside from HPA axis disturbances and proinflammatory cytokine levels, the neutrophils to lymphocytes ratio (NLR) has been evaluated as a marker of 
the impact of chronic stress on the immune system [16-18]. It appears that chronic stress may increase the NLR due to an increase in neutrophils and/or a reduction in lymphocytes in peripheral blood [16-18]. In addition to its possible implication in the inflammatory reaction to chronic stress related to psychological trauma, NLR, platelets to lymphocytes ratio (PLR) and monocytes to lymphocytes ratio (MLR) have all been evaluated as potential markers of low grade inflammation in several psychiatric disorders such as schizophrenia, bipolar disorder, suicidal behavior, opioid use disorder, attention deficit and hyperactivity disorder, etc. [19-27].

Patients with AN manifest increased secretion and concentration of the inflammatory cytokines which leads to disturbances in neutrophils and lymphocytes proliferation and activity [28]. However, it is still unclear whether the witnessed disturbances in peripheral white blood cells is related to a primary immunological predisposition in patients with AN or to a non specific end result due to malnutrition [28]. To date, the only study evaluating NLR in patients with AN has demonstrated that it is inversely correlated to bone mineral density due to inflammation's effect on bone mineralization in adolescent girls [29]. To our knowledge, there is no study that assesses the impact of CM on the immune system of patients with AN as reflected by the NLR. It is hypothesized that the chronic stress inflicted by $\mathrm{CM}$ in patients with AN may determine a specific ecophenotype characterized by heightened inflammation markers that might be reflected by disturbances in NLR. The primary objective of this study is to evaluate whether NLR is higher in patients with AN and a history of CM compared to patients with AN without a history of CM. The secondary objective of this study is to explore whether the effect of CM on the NLR in patients with AN manifests specifically in some types of maltreatment.

\section{Materials And Methods}

\section{Participants:}

All outpatients with AN according to the DSM-5 (Diagnostic and Statistical Manual of Mental Disorders) criteria who were assessed in an eating disorders unit in Montpellier, France, between March 2013 and January 2020 were eligible for the study (30). Patients with AN are referred to this daycare unit for multidisciplinary assessment, diagnostic confirmation, and management. Signed informed consent was obtained from all the participants (or from the parents of underage participants). Inclusion criteria were as follows: age superior to 15 years (15-70 years), speaking French, and having a diagnosis of AN according to DSM-5 criteria. Exclusion criteria were as follows: 1) refusing to consent, 2) having a mental disability such as intellectual deficiency or a psychotic disorder, 3) having a severe physical comorbidity, 4) suffering from an autoimmune disease or a chronic infectious disease that may alter the white blood count. The data utilized here are drawn from two large studies approved by the Ethics Committee of CPP Sud-Mediterranée IV for the first one (reference number 11-04-SC) and CPP Sud-Est 6 (reference number: AU13-13) for the second study. The two cohorts were recruited in the same way between 2013 and 2017 for the first one and 2017-2020 for the second one. The study was conducted in compliance with the World Medical Association Declaration of Helsinki.

\section{Measures:}

The multidisciplinary clinical assessment was carried out during a full day at the outpatient unit by experienced mental health professionals. The AN diagnosis was established on the basis of a nonstructured clinical assessment by psychiatrists, psychologists, and nutritionists, as well as a structured evaluation with the Mini-International Neuropsychiatric Interview (MINI, Version 5.0.0). Body weight and height were collected in a standardized way during the clinical examination. Fasting peripheral blood samples were collected from the cephalic vein between 8:00 and 9:00 a.m. in EDTA tubes. Complete blood counts were performed using a Sysmex XN-10/XN-20 Hematology Analyzer (Norderstedt, Germany). NLR was calculated by subdividing the total neutrophils count by the total lymphocytes count. In addition, participants completed the following questionnaires:

- The eating disorder examination (EDE-Q) is a 28-item screening tool used to evaluate ED symptoms. It measures disordered eating over a 28-day period and is scored across four subscales that explore the four core clinical dimensions of EDs:

Restraint, eating concern, body shape concern, weight concern [31]. The standardized Cronbach's alpha coefficient was 0.825 for the items of the EDE-Q in this sample ( 0.861 for restraint, 0.766 for eating concern, 0.902 for body shape concern and 0.834 for weight concern). 
- The Child Trauma Questionnaire (CTQ) is a 28-item self-report instrument for the retrospective assessment of trauma exposure during childhood. The CTQ consists of five subscales representing different types of trauma (physical abuse, emotional abuse, sexual abuse, physical neglect, and emotional neglect) with multiple items according to a five-point Likert scale ranging from 1 (never true) to 5 (very often true). A higher score on a subscale indicates more severe childhood trauma [32]. In line with the recommendations from Bernstein and Fink, thresholds or cut-off scores were set for each type of CM at four levels of maltreatment: none, low, moderate and severe. These were further dichotomized as moderate/severe vs. none/low, in order to minimize false identification $[33,34]$. Participants were classified in the group with moderate/severe CM $[\mathrm{CM}(+)]$ in case they presented at least one moderate/severe trauma subtype or else they have been classified in the group $\mathrm{CM}(-)$. In this sample, the standardized Cronbach's alpha coefficient was 0.838 for emotional abuse, 0.893 for physical abuse, 0.946 for sexual, 0.898 for emotional neglect and 0.501 for physical neglect. The low Cronbach's alpha coefficient for physical neglect's subscore reduces the reliability of analysis including this CM subtype but we will show them for better comprehensiveness.

\section{Statistical Analyses}

Quantitative variables significantly departing from normality assumptions (as assessed by Shapiro-Wilk test and quartile-quartile (Q-Q plots) were expressed as medians with interquartile ranges (IQR: Q1-Q3). All the variables, except for body mass index (BMI) were not normally distributed.

In a first analysis, the NLR has been compared between groups created by categorical variables. Moreover, it has been correlated with continuous variables using Spearman's rho correlation. The bivariate comparison between the groups' characteristics was conducted using the Mann-Whitney U test and Pearson's chi-square test. Nominal variables having categories with small size $(\mathrm{N}<30)$ were regrouped by merging categories. Cronbach's alpha was computed for EDE-Q total score and CTQ subscales.

In a secondary analysis, Log(NLR) has been considered as the dependant variable. An independent variable was considered in the final regression model in case it showed an influence on NLR in the bivariate analysis $(p<0.15)$. Retained continuous independent variables were classified in categories that respected their original distribution in the final regression models. Independent variables were added and retained in a forward fashion to the regression model while examining the adjusted $R^{2}$ of the ANOVA, the variance inflation factor (VIF) and the degree of freedom (df) of the model. Retained independent variables were those that assured the highest adjusted $\mathrm{R}^{2}$ and df as well as the lowest VIF. For the purpose of demonstrating the study's hypothesis, $\mathrm{CM}(+/-)$, emotional abuse and physical neglect were considered to be essential independent variables, each constituting a model of linear regression. Other retained independent variables were age, sex, relationship status and the restriction subscore of EDE-Q. Age and EDE-Q have been categorized according to quartiles. The Akaike Information Criterion (AIC) was calculated for all models created for the linear regression in order to compare the relative quality of these models according to the following formula: AIC = $\mathrm{n} \mathbf{x} \ln$ (SSres) + 2K. The model with the lowest value of the AIC was considered as the model which best represents the variability of NLR. Finally, all the statistical analyses were conducted using JASP 0.14.1.0 and SPSS 25.0.

\section{Results}

\section{Study sample:}

Overall $\mathrm{N}=206$ participants were consecutively included in the study. Participants were predominantly females $(\mathrm{N}=194,93.7 \%)$. The median age was 23.0 years old (19.5-31.1). They were most frequently single $(\mathrm{N}=149,72.3 \%)$ with high school education level $(\mathrm{N}=90,43.7 \%)$. The majority of participants were employed $(\mathrm{N}=102,49.5 \%)$. The mean of current BMl of participants was $17.71+/-2.62$. Participants belonging to the group $\mathrm{CM}(+)$ were $\mathrm{N}=86(41.7 \%)$. Participants with emotional neglect $(\mathrm{N}=55,26.7 \%)$ were the most frequently represented followed by emotional abuse $(\mathrm{N}=47,22.8 \%)$, sexual abuse $(\mathrm{N}=41,19.9 \%)$, physical neglect $(\mathrm{N}=35,17.0 \%)$ and physical abuse $(\mathrm{N}=23,11.2 \%)$. The median of NLR in the study group was $1.71(1.24-2.14)$ while that of PLR was 138.39 (109.67-180.91) and of MLR was 0.22 (0.17-0.27) (Table 1).

\section{Bivariate analysis:}


The first bivariate analysis corresponded to a comparison of NLR, PLR and MLR between the groups CM (+) and CM (-) (Table 2, Figure 1). Among all three ratios, only NLR was significantly different between these two groups $(p=0.029)$, and was the only lowgrade inflammatory marker to be further evaluated in bivariate analysis. Accordingly, NLR was correlated with age (Spearman's rho $=0.201,95 \%$ Confidence Interval $(\mathrm{Cl})=[0.06-0.33], \mathrm{p}=0.005)$ and to the restriction subscore of EDE-Q (Spearman's rho $=-0.147$, $\left.95 \% \mathrm{Cl}=\left[-5.26 \times 10^{-4}-(-0.28)\right], p=0.049\right)$. Moreover, median NLR level significantly differed according to the presence or absence of a current history of drug and/or alcohol abuse and/or dependency $(p=0.034)$. NLR also differed significantly in participants with and without a history of moderate to severe emotional abuse $(p=0.021)$ and physical neglect $(p=0.005)$ (Figure 1$)$. Finally, NLR did not present a statistical significance when compared between both genders $(p=0.087)$, both professional status categories $(p=0.087)$ and between single and married/divorced groups $(p=0.123)$. However, these variables were considered in the multivariate analysis because of their relatively low $p$ value.

\section{Multivariate analysis:}

The variability of $\log (N L R)$ has not been found to be affected by the presence of a CM $(p=0.076)$. Nonetheless, both emotional abuse $(p=0.027)$ as well as physical neglect $(p=0.008)$ significantly contributed to the variability of NLR. After comparing both models using the AIC, physical neglect seemed to be slightly better than emotional abuse as a subtype of CM explaining the variability of NLR (Table 4). However, due to the internal consistency of the physical neglect subscore of the CTQ, the variability of NLR in due to the presence of a history of emotional abuse has been considered more robust.

\section{Discussion}

In this study, we have demonstrated that chronic stress due to CM may leave an inflammatory mark detected in white blood cells count of patients with AN. As a matter of fact, NLR is significantly higher in patients with AN and a history of CM compared to patients with AN without history of $\mathrm{CM}$. This finding is in line to what has been recently demonstrated during pregnancy in women who have experienced childhood sexual abuse [35]. In this last study, NLR was significantly higher in pregnant women with a history of childhood sexual abuse independently from prenatal depression [35]. The current medical literature points towards a role of epigenetics via DNA methylation on the HPA axis dysregulation and immune system activation after CM [36]. Besides the consistent finding of HPA axis disturbances leading to lower morning cortisol levels and a flattening of the diurnal cycle in adults with a history of $\mathrm{CM}$, an accumulating body of evidence supports the fact that the immune system is chronically activated after CM [36-41]. Classically, C-reactive protein (CRP) and interleukine-6 (II-6) have been shown to be increased in adults with CM [3942]. However, after adjustment on age, sex, marital status and EDE-Q restriction score, the effect of CM on NLR was no more found in our sample. This demonstrates that the global effect of CM on NLR is multifactorial and that the variability of NLR in this population is related to the variability of other significant factors such as age, marital status and the level of eating restriction. As a matter of fact, NLR has already been shown to increase with age [43]. According to our data, eating restriction seems to inversely impact NLR variability. Indeed, the quality of consumed food may have an influence on NLR from one side, and eating restriction may induce cachexia and a subsequent hypercatabolic state from another side [44-47]. This might explain how eating restriction may exert a complex effect on the immune system independently from affecting the BMI. Nevertheless, the effect of eating restriction on NLR warrants to be studied in future studies. Finally, NLR seems to be influenced by the marital status with single participants being at a higher NLR than married/divorced ones. This might be in line with what has already been shown regarding the fact that being widowed, separated or never married may be accompanied with a significant modification in NLR levels [48]. This finding implicates that several lifestyle factors and behaviors related to marital statuses may explain immunologic differences, especially in patients with AN, that warrant further studying.

In our study, emotional abuse was associated with a higher NLR in the bivariate as well as in the multivariate analysis. Childhood abuse, in general, is known to be associated with loss of control on eating and depressive mood as symptoms leading to eating disorder's psychopathology [49]. Although anxiety and depression might be the cause for inflammation in AN, this finding has not been confirmed according to available studies on the subject in the literature [50]. However, the medical literature points towards a certain role of emotional abuse as a risk factor of inflammation. In this regard, it has been demonstrated that women who reported more emotional abuse had greater percent change in CRP over time [51]. The link between emotional abuse and the psychopathology of AN may be related to the fact that patients exposed to emotional abuse may develop emotional 
dysregulation which inhibits the emotions of anger and disgust as a part of maladaptive attitudes [52]. In a mixed-model investigation using network analysis, the childhood emotional abuse experience has been identified as the common node mediating the association between each type of CM and eating disorder's core symptoms [53]. In this same study, patients with AN restrictive type have shown that interoceptive awareness was included in the shortest pathway between emotional abuse and drive to thinness [53]. In the study conducted by Monteleone et al., emotional trauma in patients suffering from eating disorders contributed to the heightened cortisol production when exposed to stress [12]. Moreover, we have previously demonstrated that emotional abuse might be affecting the clinical severity of eating disorders through food addiction [10]. Accordingly, emotional abuse might be a subtype of CM determining a specific ecophenotype of maltreated patients with AN characterized, on the biological level by an increased HPA axis disturbances as well as an immune activation and on the clinical level by an increased interoceptive awareness, emotional dysregulation and food addiction. In this regard, emotional abuse as a CM may be perceived as a precursor event leading to emotional dysregulation as a coping mechanism which is a risk factor for food addiction and interoceptive awareness all of which being precipitated by HPA axis dysregulation while increasing low grade inflammation at the end of the cascade [54-56].

Although physical neglect's subscore presented a low reliability in our study, future studies might be interested in considering it as a factor that influences the variability of NLR. Participants with physical neglect had higher NLR than those without this subtype of CM. In one study, early institutionalization interacted with stressful life events in early adolescence to predict elevated IL-6 at age 16 among individuals with prolonged institutional care. The study results are in favor of a stress-sensitizing effect of early childhood neglect [57]. According to the stress-sensitization theory, early life deprivation may enhance reactivity to stress in later life which manifests through low grade inflammation [58,59]. An increasing amount of evidence supports the fact that early life neglect influences the child and/or adolescent's brain development and slows down its maturation [60-63]. As with emotional abuse, we have previously demonstrated that physical neglect may increase eating disorders' severity through food addiction possibly due to brain connectivity dysfunctions occurring early in life [12]. Accordingly, patients with AN and a history of physical neglect may become more sensible to stress from one side because of biological changes occurring to their brain and from another side because of clinical manifestations such as increased internalizing symptoms. This may result in an increased reactivity to stress later in life as manifested by a low grade inflammation and an increase in NLR.

Our study has however several limitations. First, assessments such as EDE-Q, CTQ, MINI were self-reported which might constitute a source of bias. For example, participants with more severe clinical dimensions of AN may more easily recall incidents of CM. Second, the subgroups with physical neglect and abuse have low numbers of patients which reduces the ability to generalize our findings. Third, the Cronbach's coefficient alpha for physical neglect subtype of the CTQ shows that the participants' answers were not consistent throughout the sample which reduces the reliability of this measure. Fourth, although multiple confounding factors have been considered in the multivariate analysis, the NLR can be affected by multiple clinical and biological determinants of AN and malnutrition so other confounding factors might have been missed in our analysis.

In conclusion, this study demonstrates that NLR is higher in patients with AN and a history of CM in general as well as in patients with AN and a history of emotional abuse in particular. The effect of CM on NLR was not present in the multivariate analysis in which age, marital status and EDE-Q restriction score seemed to influence NLR variability more significantly. However, in the multivariate analysis, emotional abuse contributed significantly to NLR's variability. Although physical neglect significantly plays the same role, caution has been taken to withdraw conclusions from this finding due to the low reliability of its measuring tool. Future studies should focus on examining the relationship between emotional abuse as a psychopathological precursor of AN from one part and the mediators between CM and NLR variability from another. These mediators might possibly be interoceptive awareness, emotional dysregulation, eating restriction, food addiction and stress sensitization.

Strength and limits: The study demonstrates that CM in general and emotional abuse in particular may be responsible of an increase in the low grade inflammation marker NLR in AN. The study's limitations, in addition to method's difficulties related to measuring childhood events, can be related to the presence of clinical and biological confounding factors influencing NLR that might have been missed in our analysis.

\section{Declarations}


Acknowledgments: None

Funding: This study received financial support from CHRU Montpellier (UF8854 and UF9804). The CHRU Montpellier had no role in the design, analysis, interpretation, or publication of this study.

Conflict of interests: None declared for all authors.

Availability of data and material: All used materials and data can be available upon request.

Code availability: Not applicable.

Ethics approval: The study protocol has been approved by the ethics committee CPP Sud-Mediterranée IV for studying the first cohort (reference number 11-04-SC) and CPP Sud-Est 6 (reference number: AU13-13) for studying the second cohort.

\section{References}

1. Smink FR, van Hoeken D, Hoek HW (2021) Epidemiology of eating disorders: incidence, prevalence and mortality rates. Curr Psychiatry Rep 14(4):406-414. doi: 10.1007/s11920-012-0282-y. PMID: 22644309, PMCID: PMC3409365.

2. Attia E (2010) Anorexia nervosa: current status and future directions. Annu Rev Med 61:425-435. doi: 10.1146/annurev.med.050208.200745. PMID: 19719398.

3. Child Maltreatment. Available online: https://www.who.int/news-room/factsheets/detail/childmaltreatment\#: :text=Child\%20maltreatment\%20is\%20the\%20abuse,under\%2018\%20years\%20of\%20age (accessed on the $11^{\text {th }}$ of july 2021).

4. Caslini M, Bartoli F, Crocamo C, Dakanalis A, Clerici M, Carrà G (2016) Disentangling the association between child abuse and eating disorders: A systematic review and meta-analysis. Psychosom Med 78(1):79-90.

5. Molendijk ML, Hoek HW, Brewerton TD, Elzinga BM (2017) Childhood maltreatment and eating disorder pathology: a systematic review and dose-response meta-analysis. Psychol Med, 1-15. doi:10.1017/S0033291716003561

6. Rijkers C, Schoorl M, van Hoeken D, Hoek HW (2019) Eating disorders and posttraumatic stress disorder. Curr Opin Psychiatry 32(6):510-517. doi:10.1097/YCo.0000000000000545

7. Racine SE, Wildes JE (2015) Emotion dysregulation and anorexia nervosa: an exploration of the role of childhood abuse. Int J Eat Disord 48(1):55-58. doi:10.1002/eat.22364

8. Rai T, Mainali P, Raza A, Rashid J, Rutkofsky I (2019) Exploring the Link Between Emotional Child Abuse and Anorexia Nervosa: A Psychopathological Correlation. Cureus 11(8):e5318. doi:10.7759/cureus.5318

9. Kong S, Bernstein K (2009) Childhood trauma as a predictor of eating psychopathology and its mediating variables in patients with eating disorders. J Clin Nurs 18(13):1897-1907. doi:10.1111/j.1365-2702.2008.02740.x

10. Bou Khalil R, Sleilaty G, Richa S, Seneque M, Iceta S, Rodgers R, Alacreu-Crespo A, Maimoun L, Lefebvre P, Renard E, Courtet P, Guillaume S (2020) The Impact of Retrospective Childhood Maltreatment on Eating Disorders as Mediated by Food Addiction: A Cross-Sectional Study. Nutrients 12(10):2969. doi: 10.3390/nu12102969. PMID: 32998411, PMCID: PMC7601309.

11. Monteleone AM, Patriciello G, Ruzzi V, Cimino M, Giorno CD, Steardo L Jr, Monteleone P, Maj M (2018) Deranged emotional and cortisol responses to a psychosocial stressor in anorexia nervosa women with childhood trauma exposure: Evidence for a "maltreated ecophenotype"? J Psychiatr Res 104:39-45. doi: 10.1016/j.jpsychires.2018.06.013. Epub 2018 Jun 19. PMID: 29936175.

12. Monteleone AM, Cascino G, Ruzzi V, Pellegrino F, Patriciello G, Barone E, Carfagno M, Monteleone P, Maj M (2021) Emotional traumatic experiences significantly contribute to identify a maltreated ecophenotype sub-group in eating disorders: Experimental evidence. Eur Eat Disord Rev 29(2):269-280. doi: 10.1002/erv.2818. Epub 2020 Dec 30. PMID: 33378110.

13. Nance DM, Sanders VM (2007) Autonomic innervation and regulation of the immune system (1987-2007). Brain Behav Immun 21(6):736-45. doi: 10.1016/j.bbi.2007.03.008. Epub 2007 Apr 27. PMID: 17467231, PMCID: PMC1986730. 
14. Kim YK, Amidfar M, Won E (2019) A review on inflammatory cytokine-induced alterations of the brain as potential neural biomarkers in post-traumatic stress disorder. Prog Neuropsychopharmacol Biol Psychiatry 91:103-112. doi:

10.1016/j.pnpbp.2018.06.008. Epub 2018 Jun 19. PMID: 29932946.

15. Miller MW, Lin AP, Wolf EJ, Miller DR (2018) Oxidative Stress, Inflammation, and Neuroprogression in Chronic PTSD. Harv Rev Psychiatry 26(2):57-69. doi: 10.1097/HRP.0000000000000167.

16. Swan MP, Hickman DL (2014) Evaluation of the neutrophil-lymphocyte ratio as a measure of distress in rats. Lab Anim (NY) 43(8):276-82. doi: 10.1038/laban.529. PMID: 25050728.

17. Hickman DL (2017) Evaluation of the neutrophil:lymphocyte ratio as an indicator of chronic distress in the laboratory mouse. Lab Anim (NY) 46(7):303-307. doi: 10.1038/laban.1298. PMID: 28644453, PMCID: PMC7091828.

18. Penz M, Kirschbaum C, Buske-Kirschbaum A, Wekenborg MK, Miller R (2018) Stressful life events predict one-year change of leukocyte composition in peripheral blood. Psychoneuroendocrinology 94:17-24. doi: 10.1016/j.psyneuen.2018.05.006.

19. Özdin S, Sarisoy G, Böke Ö (2017) A comparison of the neutrophil-lymphocyte, platelet-lymphocyte and monocytelymphocyte ratios in schizophrenia and bipolar disorder patients - a retrospective file review. Nord J Psychiatry 71(7):509512. doi: $10.1080 / 08039488.2017 .1340517$.

20. Avcil S (2018) Evaluation of the neutrophil/lymphocyte ratio, platelet/lymphocyte ratio, and mean platelet volume as inflammatory markers in children with attention-deficit hyperactivity disorder. Psychiatry Clin Neurosci 72(7):522-530. doi: 10.1111/pcn.12659.

21. Orum MH, Kara MZ, Egilmez OB, Kalenderoglu A (2018) Complete blood count alterations due to the opioid use: what about the lymphocyte-related ratios, especially in monocyte to lymphocyte ratio and platelet to lymphocyte ratio? J Immunoassay Immunochem 39(4):365-376. doi: 10.1080/15321819.2018.1460272.

22. Inanli I, Aydin M, Çaliskan AM, Eren I (2019) Neutrophil/lymphocyte ratio, monocyte/lymphocyte ratio, and mean platelet volume as systemic inflammatory markers in different states of bipolar disorder. Nord J Psychiatry 73(6):372-379. doi: 10.1080/08039488.2019.1640789.

23. Velasco Á, Rodríguez-Revuelta J, Olié E, Abad I, Fernández-Peláez A, Cazals A, Guillaume S, de la Fuente-Tomás L, JiménezTreviño L, Gutiérrez L, García-Portilla P, Bobes J, Courtet P, Sáiz PA (2020) Neutrophil-to-lymphocyte ratio: A potential new peripheral biomarker of suicidal behavior. Eur Psychiatry 63(1):e14. doi: 10.1192/j.eurpsy.2019.20.

24. Yu Q, Weng W, Zhou H, Tang Y, Ding S, Huang K, Liu Y (2020) Elevated Platelet Parameter in First-Episode Schizophrenia Patients: A Cross-Sectional Study. J Interferon Cytokine Res 40(11):524-529. doi: 10.1089/jir.2020.0117.

25. Fusar-Poli L, Natale A, Amerio A, Cimpoesu P, Grimaldi Filioli P, Aguglia E, Amore M, Serafini G, Aguglia A (2021) Neutrophil-toLymphocyte, Platelet-to-Lymphocyte and Monocyte-to-Lymphocyte Ratio in Bipolar Disorder. Brain Sci 11(1):58. doi: 10.3390/brainsci11010058. PMID: 33418881, PMCID: PMC7825034.

26. Dionisie V, Filip GA, Manea MC, Movileanu RC, Moisa E, Manea M, Riga S, Ciobanu AM (2021) Neutrophil-to-Lymphocyte Ratio, a Novel Inflammatory Marker, as a Predictor of Bipolar Type in Depressed Patients: A Quest for Biological Markers. J Clin Med 10(9):1924. doi: 10.3390/jcm10091924.

27. Zhu X, Zhou J, Zhu Y, Yan F, Han X, Tan Y, Li R (2021) Neutrophil/lymphocyte, platelet/lymphocyte and monocyte/lymphocyte ratios in schizophrenia. Australas Psychiatry. 2021 Jun 16:10398562211022753. doi: 10.1177/10398562211022753.

28. Gibson D, Mehler PS (2019) Anorexia Nervosa and the Immune System-A Narrative Review. J Clin Med 8(11):1915. doi: 10.3390/jcm8111915.

29. Morawiecka-Pietrzak MT, Malczyk Ż, Dąbrowska E, Blaska M, Pietrzak M, Gliwińska A, Góra A, Ziora K, Pluskiewicz W, Ostrowska Z (2021) The Relationship of Neutrophil-to-Lymphocyte Ratio and Platelet-to-Lymphocyte Ratio with Bone Mineral Density in adolescent girls suffering from anorexia nervosa. Endokrynol Pol. 2021 May 19. doi: 10.5603/EP.a2021.0036.

30. APA. Diagnostic and Statistical Manual of Mental Disorders (5th ed.) (2013) Arlington, VA: American Psychiatric Publishing.

31. Fairburn CG, Beglin SJ (1994) Assessment of eating disorders: interview or self-report questionnaire?. Int J Eat Disord 16(4):363-370.

32. Bernstein DP, Fink L (1998) Childhood trauma questionnaire: A retrospective self-report. The Psychological Corporation: San Antonio. 
33. Choi JY, Choi YM, Gim MS, Park JH, Park SH (2014) The effects of childhood abuse on symptom complexity in a clinical sample: mediating effects of emotion regulation difficulties. Child Abuse Negl 38(8):1313-1319.

doi:10.1016/j.chiabu.2014.04.016

34. Min M, Farkas K, Minnes S, Singer LT (2007) Impact of childhood abuse and neglect on substance abuse and psychological distress in adulthood. J Trauma Stress 20(5):833-844. doi:10.1002/jts.20250

35. Bublitz MH, Freeburg T, Sharp M, Salameh M, Bourjeily G (2021) Childhood adversity, prenatal depression, and maternal inflammation across pregnancy. Obstetric Medicine : 1753495X211011910

36. Gonzalez A (2013) The impact of childhood maltreatment on biological systems: Implications for clinical interventions. Paediatr Child Health 18(8):415-418.

37. Bremner JD, Vermetten E, Kelley ME (2007) Cortisol, dehydroepiandrosterone, and estradiol measured over 24 hours in women with childhood sexual abuse-related posttraumatic stress disorder. J Nerv Ment Dis 195:919-927.

38. Power C, Thomas C, Li L, Hertzman C (2012) Childhood psychosocial adversity and adult cortisol patterns. Br J Psychiatry 201:199-206.

39. Carpenter LL, Gawunga CE, Tykra AR, Lee JK, Anderson GM, Price LH (2010) Association between plasma IL-6 response to acute stress and early-life adversity in healthy adults. Neuropsychopharmacology 35:2617-2623.

40. Danese A, Pariante CM, Caspi A, Taylor A, Poulton R (2007) Childhood maltreatment predicts adult inflammation in a lifecourse study. Proc Natl Acad Sci USA 104:1319-24.

41. Bertone-Johnson ER, Whitcomb BW, Missmer SA, Karlson EW, Rich-Edwards JW (2012) Inflammation and early-life abuse in women. Am J Prev Med 43:611-620.

42. Coelho R, Viola TW, Walss-Bass C, Brietzke E, Grassi-Oliveira R (2014) Childhood maltreatment and inflammatory markers: a systematic review. Acta Psychiatr Scand 129(3):180-92. doi: 10.1111/acps.12217.

43. Lin BD, Hottenga JJ, Abdellaoui A, Dolan CV, de Geus EJC, Kluft C, Boomsma DI, Willemsen G (2016) Causes of variation in the neutrophil-lymphocyte and platelet-lymphocyte ratios: a twin-family study. Biomark Med 10(10):1061-1072. doi: 10.2217/bmm-2016-0147.

44. Wang R, Chen PJ, Chen WH (2011) Diet and exercise improve neutrophil to lymphocyte ratio in overweight adolescents. Int J Sports Med 32(12):982-6. doi: 10.1055/s-0031-1283185.

45. Rodríguez-Rodríguez E, López-Sobaler AM, Ortega RM, Delgado-Losada ML, López-Parra AM, Aparicio A (2020) Association between Neutrophil-to-Lymphocyte Ratio with Abdominal Obesity and Healthy Eating Index in a Representative Older Spanish Population. Nutrients 12(3):855. doi:10.3390/nu12030855

46. Barker T, Fulde G, Moulton B, Nadauld LD, Rhodes T (2020) An elevated neutrophil-to-lymphocyte ratio associates with weight loss and cachexia in cancer. Sci Rep 10(1):7535. doi:10.1038/s41598-020-64282-z

47. Palmacci F, Toti E, Raguzzini A, Catasta G, Aiello P, Peluso I, Biava M, Palmery M (2019) Neutrophil-to-Lymphocyte Ratio, Mediterranean Diet, and Bone Health in Coeliac Disease Patients: A Pilot Study. Oxid Med Cell Longev 2019:7384193. doi: 10.1155/2019/7384193.

48. Howard R, Scheiner A, Kanetsky PA, Egan KM (2019) Sociodemographic and lifestyle factors associated with the neutrophilto-lymphocyte ratio. Ann Epidemiol 38:11-21.e6. doi: 10.1016/j.annepidem.2019.07.015.

49. Rodgers RF, DuBois R, Thiebaut S, Jaussent I, Maimoun L, Seneque M, Lefebvre P, Renard E, Courtet P, Guillaume S (2019) Structural differences in eating disorder psychopathology after history of childhood abuse: Insights from a Bayesian network analysis. J Abnorm Psychol 128(8):795-805. doi: 10.1037/abn0000470.

50. Dalton B, Bartholdy S, Robinson L, Solmi M, Ibrahim MAA, Breen G, Schmidt U, Himmerich H (2018) A meta-analysis of cytokine concentrations in eating disorders. J Psychiatr Res. 2018 Aug,103:252-264. doi: 10.1016/j.jpsychires.2018.06.002.

51. Matthews KA, Chang YF, Thurston RC, Bromberger JT (2014) Child abuse is related to inflammation in mid-life women: role of obesity. Brain Behav Immun 36:29-34. doi:10.1016/j.bbi.2013.09.013

52. Rai T, Mainali P, Raza A, Rashid J, Rutkofsky I (2019) Exploring the Link Between Emotional Child Abuse and Anorexia Nervosa: A Psychopathological Correlation. Cureus 11(8):e5318. doi: 10.7759/cureus.5318. 
53. Monteleone AM, Tzischinsky O, Cascino G, Alon S, Pellegrino F, Ruzzi V, Latzer Y (2021) The connection between childhood maltreatment and eating disorder psychopathology: a network analysis study in people with bulimia nervosa and with binge eating disorder. Eat Weight Disord. 2021 Mar 28. doi: 10.1007/s40519-021-01169-6. Epub ahead of print.

54. Parylak SL, Koob GF, Zorrilla EP (2011) The dark side of food addiction. Physiol Behav 104(1):149-156. doi:10.1016/j.physbeh.2011.04.063

55. Wiss DA, Avena N, Gold M (2020) Food Addiction and Psychosocial Adversity: Biological Embedding, Contextual Factors, and Public Health Implications. Nutrients 12(11):3521. doi: 10.3390/nu12113521.

56. Pivarunas B, Conner BT (2015) Impulsivity and emotion dysregulation as predictors of food addiction. Eat Behav. 2015 Dec,19:9-14. doi: 10.1016/j.eatbeh.2015.06.007.

57. Tang A, Wade M, Fox NA, Nelson CA, Zeanah CH, Slopen N (2020) The prospective association between stressful life events and inflammation among adolescents with a history of early institutional rearing. Dev Psychopathol 32(5):1715-1724. doi: $10.1017 /$ S0954579420001479.

58. La Rocque CL, Harkness KL, Bagby RM (2014) The differential relation of childhood maltreatment to stress sensitization in adolescent and young adult depression. J Adolesc 37(6):871-882. doi: 10.1016/j.adolescence.2014.05.012.

59. Wade M, Zeanah CH, Fox NA, Tibu F, Ciolan LE, Nelson CA (2019) Stress sensitization among severely neglected children and protection by social enrichment. Nat Commun 10(1):5771. doi: 10.1038/s41467-019-13622-3.

60. Sheridan MA, Fox NA, Zeanah CH, McLaughlin KA, Nelson CA $3^{\text {rd }}(2012)$ Variation in neural development as a result of exposure to institutionalization early in childhood. Proc Natl Acad Sci U S A 109(32):12927-32. doi: 10.1073/pnas.1200041109.

61. Herringa RJ, Birn RM, Ruttle PL, Burghy CA, Stodola DE, Davidson RJ, Essex MJ (2013) Childhood maltreatment is associated with altered fear circuitry and increased internalizing symptoms by late adolescence. Proc Natl Acad Sci U S A 110(47):19119-24. doi: 10.1073/pnas.1310766110.

62. Hostinar CE, Stellern SA, Schaefer C, Carlson SM, Gunnar MR (2012) Associations between early life adversity and executive function in children adopted internationally from orphanages. Proc Natl Acad Sci U S A 109 Suppl 2(Suppl 2):17208-12. doi: 10.1073/pnas.1121246109.

63. McCrory E, De Brito SA, Viding E (2010) Research review: the neurobiology and genetics of maltreatment and adversity. J Child Psychol Psychiatry 51(10):1079-95. doi: 10.1111/j.1469-7610.2010.02271.x.

\section{Tables}

Table 1: Description of sociodemographic, clinical and biological variables of $\mathrm{N}=206$ participants with AN included in the study sample. 


\begin{tabular}{|c|c|c|}
\hline \multirow[t]{4}{*}{ Variable } & \multirow[t]{4}{*}{ Category } & Description \\
\hline & & $\mathrm{N}(\%)$ for categorical variables \\
\hline & & Median (Q1-Q3) for continuous variables \\
\hline & & $\begin{array}{l}\text { Mean +/- standard deviation for normally } \\
\text { distributed continuous variables }\end{array}$ \\
\hline \multirow[t]{2}{*}{ Sex } & Male & $12(5.82 \%)$ \\
\hline & Female & $194(94.17 \%)$ \\
\hline Age & & $23.01(19.46-31.11)$ \\
\hline \multirow[t]{2}{*}{ Marital status } & Single & $149(72.33 \%)$ \\
\hline & Married/divorced & $54(25.83)$ \\
\hline \multirow[t]{3}{*}{ Education level } & High school level & $90(43.68 \%)$ \\
\hline & License or master's university level & $74(35.92 \%)$ \\
\hline & Doctorate level & $23(11.16 \%)$ \\
\hline \multirow[t]{2}{*}{ Professional status } & $\begin{array}{l}\text { Office work (Employee, manager, } \\
\text { intermediate status) }\end{array}$ & 79 (38.35\%) \\
\hline & $\begin{array}{l}\text { Manual work (agriculture, } \\
\text { craftsman, worker, other) }\end{array}$ & $126(61.16 \%)$ \\
\hline Current BMI & & $17.71+/-2.62$ \\
\hline \multirow[t]{2}{*}{ Nicotine consumption } & Yes & 70 (33.98\%) \\
\hline & No & $132(63.59 \%)$ \\
\hline \multirow[t]{2}{*}{ Current Depression } & Yes & $58(28.15 \%)$ \\
\hline & No & $126(61.16 \%)$ \\
\hline \multirow[t]{2}{*}{ Current PTSD } & Yes & $11(5.34 \%)$ \\
\hline & No & $173(83.98 \%)$ \\
\hline \multirow{2}{*}{$\begin{array}{l}\text { Current drug and or alcohol } \\
\text { dependence and/or abuse }\end{array}$} & Yes & $10(4.85 \%)$ \\
\hline & No & $171(83.01 \%)$ \\
\hline \multirow[t]{2}{*}{ History of suicide attempt } & Yes & $38(18.44 \%)$ \\
\hline & No & $165(85.09 \%)$ \\
\hline \multirow[t]{5}{*}{ EDE-Q } & Total score & $3.32(1.87-4.35)$ \\
\hline & Restriction & $3.6(1.35-4.8)$ \\
\hline & Eating concern & $2.8(1.4-3.8)$ \\
\hline & Weight concern & $3.6(1.6-4.8)$ \\
\hline & Shape concern & $4.12(2.37-5.25)$ \\
\hline NLR & & $1.71(1.24-2.14)$ \\
\hline PLR & & 138.39 (109.67-180.91) \\
\hline MLR & & $0.22(0.17-0.27)$ \\
\hline \multirow[t]{2}{*}{$\mathrm{CM}(+/-)$} & $\mathrm{CM}(+)$ & $86(41.74 \%)$ \\
\hline & $\mathrm{CM}(-)$ & $102(49.51 \%)$ \\
\hline
\end{tabular}

Page $11 / 15$ 
Emotional abuse

Physical abuse

Sexual abuse

Emotional neglect

Physical neglect
47 (22.81\%)

$23(11.16 \%)$

41 (19.9\%)

$55(26.69 \%)$

$35(16.99 \%)$

Table 2: Bivariate comparison of NLR, PLR and MLR levels in groups of patients with AN between $\mathrm{CM}(+)$ and $\mathrm{CM}(-)$.

\begin{tabular}{|lllll|}
\hline Variable & $\begin{array}{l}\text { Group } \mathrm{CM}(+)(\mathrm{N}=86) \\
\text { Median }(\mathrm{Q} 1-\mathrm{Q} 3)\end{array}$ & $\begin{array}{l}\text { Group } \mathrm{CM}(-)(\mathrm{N}=102) \\
\text { Median }(\mathrm{Q} 1-\mathrm{Q} 3)\end{array}$ & Test and $\mathrm{p}$ value & $\mathrm{P}$ value \\
\hline NLR & $1.84(1.4-2.28)$ & $1.62(1.2-2)$ & $\mathrm{MWU}$ & $\mathbf{p}=\mathbf{0 . 0 2 9}$ \\
\hline PLR & $140.54(119.33-180.53)$ & $135.81(102.39-172.78)$ & $\mathrm{MWU}$ & $\mathrm{p}=0.344$ \\
\hline MLR & $0.22(0.18-0.28)$ & $0.2(0.17-0.27)$ & $\mathrm{MWU}$ & $\mathrm{p}=0.34$ \\
\hline
\end{tabular}

Table 3: Bivariate comparison of NLR levels with sociodemographic and clinical categorical variables as well as correlation with sociodemographic and clinical continuous variables. 


\begin{tabular}{|c|c|c|c|c|}
\hline Variable & Category & $\begin{array}{l}\text { Median (Q1-Q3) of NLR in } \\
\text { different categories }\end{array}$ & Statistical test & $\begin{array}{l}P \\
\text { value }\end{array}$ \\
\hline \multirow[t]{2}{*}{ Sex } & Male & $1.44(0.87-1.79)$ & \multirow[t]{2}{*}{ MWU } & \multirow[t]{2}{*}{0.087} \\
\hline & Female & $1.85(1.29-2.14)$ & & \\
\hline \multirow[t]{2}{*}{ Age } & & & $\begin{array}{l}\text { Spearman's rho }= \\
0.201\end{array}$ & \multirow[t]{2}{*}{0.005} \\
\hline & & & [0.06-0.33] & \\
\hline \multirow[t]{2}{*}{ Marital status } & Single & $1.73(1.29-2.2)$ & \multirow[t]{2}{*}{ MWU } & \multirow[t]{2}{*}{0.123} \\
\hline & Married/divorced & $1.55(1.18-1.97)$ & & \\
\hline \multirow[t]{3}{*}{ Education level } & High school level & $1.72(1.29-2.12)$ & \multirow[t]{3}{*}{ KW } & \multirow[t]{3}{*}{0.624} \\
\hline & $\begin{array}{l}\text { License or master's university } \\
\text { level }\end{array}$ & $1.76(1.3-2.15)$ & & \\
\hline & Doctorate university level & $1.41(1.06-2.15)$ & & \\
\hline \multirow[t]{2}{*}{ Professional status } & $\begin{array}{l}\text { Office work (Employee, } \\
\text { manager, intermediate status) }\end{array}$ & $1.81(1.39-2.28)$ & \multirow[t]{2}{*}{ MWU } & \multirow[t]{2}{*}{0.087} \\
\hline & $\begin{array}{l}\text { Manual work (agriculture, } \\
\text { craftsman, worker, other) }\end{array}$ & $1.67(1.2-2.08)$ & & \\
\hline \multirow[t]{2}{*}{ Current BMI } & & & $\begin{array}{l}\text { Pearson's } r=0.065 \\
{[-0.075-0.203]}\end{array}$ & 0.404 \\
\hline & & & Spearman's rho: & \\
\hline \multirow[t]{7}{*}{ EDE-Q } & Total score & & \multirow{2}{*}{$\begin{array}{l}-0.037 \\
0.114]\end{array}[-0.186-$} & 0.632 \\
\hline & Restriction & & & 0.049 \\
\hline & Eating concern & & $\begin{array}{l}-0.147\left[-5.26 \times 10^{-4}-\right. \\
(-0.28)]\end{array}$ & 0.837 \\
\hline & Weight concern & & \multirow{2}{*}{$\begin{array}{l}-0.016[-0.163- \\
0.132]\end{array}$} & 0.649 \\
\hline & Shape concern & & & 0.957 \\
\hline & & & $\begin{array}{l}0.035[-0.114- \\
0.182]\end{array}$ & \\
\hline & & & $\begin{array}{l}-0.004[-0.153- \\
0.145]\end{array}$ & \\
\hline \multirow[t]{2}{*}{ Nicotine consumption } & Yes & $1.81(1.22-2.15)$ & \multirow[t]{2}{*}{ MWU } & \multirow[t]{2}{*}{0.368} \\
\hline & No & $1.65(1.25-2.13)$ & & \\
\hline \multirow[t]{2}{*}{ Current Depression } & Yes & $1.78(1.3-2.29)$ & \multirow[t]{2}{*}{ MWU } & \multirow[t]{2}{*}{0.301} \\
\hline & No & $1.7(1.3-2.13)$ & & \\
\hline \multirow[t]{2}{*}{ Current PTSD } & Yes & $1.72(1.44-2)$ & \multirow[t]{2}{*}{ MWU } & \multirow[t]{2}{*}{0.789} \\
\hline & No & $1.72(1.28-2.14)$ & & \\
\hline \multirow{2}{*}{$\begin{array}{l}\text { Current drug and or alcohol } \\
\text { dependence and/or abuse }\end{array}$} & Yes & $2.16(1.86-2.66)$ & \multirow[t]{2}{*}{ MWU } & 0.034 \\
\hline & No & $1.7(1.3-2.13)$ & & \\
\hline History of suicide attempt & Yes & $1.79(1.24-2.28)$ & MWU & 0.622 \\
\hline & No & $1.71(1.21-2.12)$ & & \\
\hline Subtype of CM & Emotional abuse & Yes, 2.04 (1.4-2.29) & MWU & 0.021 \\
\hline & & No, 1.64 (1.2-2.05) & & \\
\hline
\end{tabular}




\begin{tabular}{llll|} 
Physical abuse & Yes, $1.73(1.56-2.18)$ & MWU & 0.407 \\
No, $1.72(1.22-2.13)$ & & \\
Sexual abuse & Yes, $1.79(1.26-2.28)$ & MWU & 0.508 \\
No, $1.7(1.28-2.12)$ & & \\
Emotional neglect & Yes, $1.82(1.42-2.28)$ & MWU & 0.196 \\
Physical neglect & No, $1.71(1.2-2.13)$ & & 0.005 \\
& Yes, $1.92(1.71-2.36)$ & MWU & \\
\hline
\end{tabular}

Table 4: Three models (each including different category or subtype of $\mathrm{CM}$ ) as independent variables of multivariate linear regression analysis of NLR as a dependent variable.

\begin{tabular}{|c|c|c|c|c|c|c|}
\hline $\begin{array}{l}\text { Independent } \\
\text { variable }\end{array}$ & $\begin{array}{l}\text { Model } 1 \text { with } \\
\text { CM (+/-) } \\
\text { (standardized } \\
\text { coefficient } \beta \text {, } \\
\text { p value) }\end{array}$ & $\begin{array}{l}\text { Model } 1 \\
\text { characteristics }\end{array}$ & $\begin{array}{l}\text { Model } 2 \text { with } \\
\text { emotional abuse } \\
\text { (standardized } \\
\text { coefficient } \beta, \mathrm{p} \\
\text { value) }\end{array}$ & $\begin{array}{l}\text { Model } 2 \\
\text { characteristics }\end{array}$ & $\begin{array}{l}\text { Model } 3 \text { with } \\
\text { physical neglect } \\
\text { (standardized } \\
\text { coefficient } \beta, p \\
\text { value) }\end{array}$ & $\begin{array}{l}\text { Model } 3 \\
\text { characteristics }\end{array}$ \\
\hline $\mathrm{CM}$ & $\begin{array}{l}(0.31 \\
p=0.076)\end{array}$ & \multirow[t]{2}{*}{$\begin{array}{l}\text { Adjusted } \\
\mathrm{R}^{2}=0.122\end{array}$} & $(0.17, p=0.027)$ & \multirow[t]{2}{*}{$\begin{array}{l}\text { Adjusted } \\
\mathrm{R}^{2}=0.137\end{array}$} & $(0.194, p=0.008)$ & \multirow[t]{2}{*}{$\begin{array}{l}\text { Adjusted } \\
\mathrm{R}^{2}=0.144\end{array}$} \\
\hline Age & $\begin{array}{l}(0.213, \\
p=0.008)\end{array}$ & & $(0.212, p=0.008)$ & & $(0.218, p=0.005)$ & \\
\hline Sex & $\begin{array}{l}(0.164 \\
p=0.024)\end{array}$ & $P<0.001$ & $\begin{array}{l}(0.153, \\
p=0.035)\end{array}$ & $P<0.001$ & $(0.156, p=0.031)$ & $P<0.001$ \\
\hline $\begin{array}{l}\text { Marital } \\
\text { status }\end{array}$ & $\begin{array}{l}(-0.286 \\
p<0.001)\end{array}$ & $d f=167$ & $(-0.31, \mathbf{p}<0.001)$ & $d f=164$ & $\begin{array}{l}(-0.281 \\
p<0.001)\end{array}$ & $d f=164$ \\
\hline $\begin{array}{l}\text { EDE-Q } \\
\text { restriction }\end{array}$ & $\begin{array}{l}(-0.186 \\
p=0.011)\end{array}$ & $\mathrm{AIC}=251.69$ & $(-0.193, p=0.009)$ & $\mathrm{AIC}=252.7$ & $\begin{array}{l}(-0.195 \\
p=0.007)\end{array}$ & $A I C=252.55$ \\
\hline
\end{tabular}

Figures 


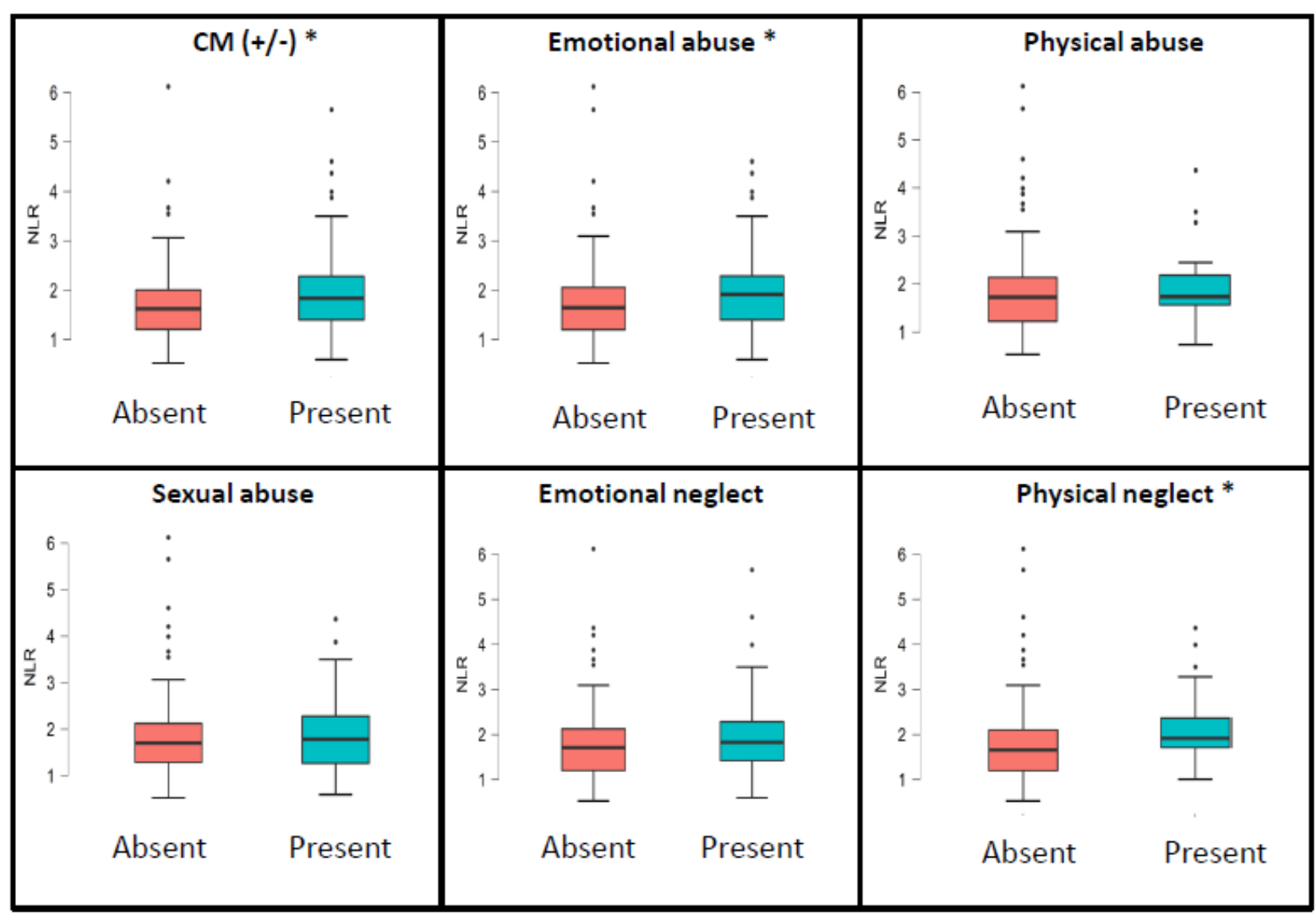

Figure 1

Comparison between NLR levels in patients with AN categorized according to their history status of CM as well as different CM subtypes. ${ }^{*} \mathrm{p}<0.05$ 